\title{
The Corrosive Improvement with High Temperature Laser Surface Treatment of AA7075
}

\section{Ruiming Su ( $\square$ suruiming1984@126.com )}

Shenyang University of Technology

\section{Lei Wang}

Shenyang University of Technology

\section{Kaining Wang}

Shenyang University of Technology

\section{Guanglong Li}

Shenyang University of Technology

\section{Yingdong Qu}

Shenyang University of Technology

\section{Rongde Li}

Shenyang University of Technology

\section{Research Article}

Keywords: laser high temperature pre-precipitation, $\mathrm{Al}-\mathrm{Zn}-\mathrm{Mg}-\mathrm{Cu}$ alloy, exfoliation corrosion, intergranular corrosion, polarization curves

Posted Date: April 6th, 2021

DOl: https://doi.org/10.21203/rs.3.rs-365647/v1

License: (1) (1) This work is licensed under a Creative Commons Attribution 4.0 International License.

Read Full License 


\section{Abstract}

a recently developed AA7075 was subjected to solid solution, high temperature laser surface treatment and artificial aging. The microstructure evolution and precipitation behavior were examined, and their effects on corrosion behavior and corrosion cracking were analyzed. The results show that the coarse $\eta$ phase disappears and a large number of smaller $\eta$ phases are formed after high temperature laser surface treatment. Most of the phases dissolved into Al matrix during solution, a fine $\eta$ phase precipitated in laser treatment. $\eta$ ' appeared in the high temperature laser surface treatment samples. It was concluded that reasonable laser scanning power owned the best corrosion resistance, lower intergranular corrosion tendency. Both lower laser scan power and higher scan power samples were susceptible to the intergranular corrosion, and the intergranular cracking was observed. In contrary, the reasonable sample which the laser power is $1000 \mathrm{~W}$ showed much better corrosion resistance due to the coarsening and separation of grain boundary precipitations.

\section{Introduction}

AA7075 has attracted much attention due to its excellent combination of low density, high specific strength, ductility, toughness and resistance to fatigue and corrosion[1, 2]. AA7075 has been widely used for manufacturing of aircraft structural wings components from riveting and welding[3, 4]. However, the high proportion of magnesium and zinc in the alloy, make the corrosion resistance of the alloy poor[5]. At present, the mainstream view is divided into two kinds: the new precipitation is formed by adding other elements. The new precipitation enhances the corrosion resistance of the alloy without changing the original mechanical properties[6, 7]. Furthermore, heat treatment also can improve the corrosion resistance of the alloy. The mechanical properties of the alloy can be enhanced with T6 temper[8, 9]. The corrosion resistance of the alloy also can be improved with T73 treatment. But the mechanical properties of the alloy have decreased[10-12]. Su proposed retrogression and re-aging treatment, the mechanical properties and corrosion resistance of the alloy can be improved by short time retrogression treatment[1316]. In recent years, Huang have proposed high temperature pre-precipitation (HTPP) process, which can precipitate supersaturated solid solution in advance and achieve better performance and better corrosion resistance than T6 temper[17-20]. However, due to the high temperature requirement of the preprecipitation, the shortest HTPP process time also takes half an hour. The long heat time cause the phase of the previous precipitation agglomerated. A large precipitation is formed. The performance of the alloy is reduced. It needs a process which has a short time and a high energy to replace the heating process. The laser surface treatment technique allows the change in the properties and shape of the alloy. Laser surface treatment has also been developed in many applications, particularly in the aerospace industry[21-23]. The heating speed of the laser is fast, and the heating time is short. Thus, this method can replace the HTPP process.

Therefore, in this work, the HTPP process was replaced with the laser high temperature pre-precipitation (LHTPP) process. The corrosion behavior of the AA7075 treated with LHTPP process was studied using exfoliation corrosion, intergranular corrosion, cyclic polarization, electrochemical impedance 
spectroscopy (EIS), and transmission electron microscopy (TEM) to obtain further insight into the mechanism of chloride-driven corrosion of the alloy. The trends of the changes in the process parameters are summarized. To improve the mechanical properties and corrosion resistance of the AA7075, it is necessary to select the appropriate process parameters.

\section{Experimental}

The chemical composition of the AA7075 is listed in Table 1.

Table 1 Chemical composition of the AA7075 (\%, mass fraction)

\begin{tabular}{|llllllll|}
\hline $\mathrm{Zn}$ & $\mathrm{Mg}$ & $\mathrm{Cu}$ & $\mathrm{Cr}$ & $\mathrm{Mn}$ & $\mathrm{Fe}$ & $\mathrm{Si}$ & $\mathrm{Al}$ \\
\hline 5.91 & 2.4 & 1.5 & 0.18 & 0.03 & 0.17 & 0.09 & Bal. \\
\hline
\end{tabular}

The heat treatment process for the alloy was treated at $450{ }^{\circ} \mathrm{C}$ for $1 \mathrm{hr}$. and $470{ }^{\circ} \mathrm{C}$ for $2 \mathrm{hr}$. Table 2 lists the different laser treatment parameters. Figure 1 is the schematic diagram of high temperature laser surface treatment process. Laser power is experimental variable. Laser scanning speed is $3 \mathrm{~mm} / \mathrm{s}$, and constant temperature $25^{\circ} \mathrm{C}$ in the laboratory. After the laser treatment processing the samples was aged at $120^{\circ} \mathrm{C}$ for $16 \mathrm{hr}$. It is pointed out that one sample was only treated with T6 temper. After the laser treatment processing the samples was aged at $120^{\circ} \mathrm{C}$ for $16 \mathrm{hr}$.

The exfoliation corrosion tests were performed in accordance with ASTM G34-01 (2013). The compositions of the test solution were $4 \mathrm{~mol} \mathrm{NaCl}, 0.5 \mathrm{~mol} \mathrm{KNO}_{3}$ and $0.1 \mathrm{~mol} \mathrm{HNO}_{3}$. The solution was maintained $25 \pm 3{ }^{\circ} \mathrm{C}$ during the whole test. The test duration is $48 \mathrm{hr}$. The ratings for the exfoliation corrosion were established according to the standard paragraphs EA to ED. The standard of ASTM G1101992 (2009) was referred to evaluate the intergranular corrosion (IGC) resistance of heat treatable aluminum alloys by immersion in a solution with $57 \mathrm{~g}$ of $\mathrm{NaCl}$ and $10 \mathrm{~mL}$ of $\mathrm{H}_{2} \mathrm{O}_{2}$, respectively, in a $1 \mathrm{~L}$ distilled water. The specimen in the solution was maintained at temperature of $30 \pm 3{ }^{\circ} \mathrm{C}$ for $6 \mathrm{hr}$. The microstructure and phase distribution of the samples were observed by JEM-2100 transmission electron microscope. The electrochemical measurements were carried out using a CS310 electrochemical system, and the dynamic polarization curve of the electric potential was obtained. A three-electrode system was used in the experiment with the reference electrode with a Luggin capillary, the auxiliary electrode and a cube sample with side length of $10 \mathrm{~mm}$; the reference electrode was a saturated calomel electrode, and the auxiliary electrode was a platinum electrode. The solvent medium of the system was a $\mathrm{NaCl}$ solution with a concentration of $0.1 \mathrm{~mol} / \mathrm{L}$, and the temperature was $25 \pm 1^{\circ} \mathrm{C}$; soaking was carried out for $1 \mathrm{hr}$. The open circuit potential was measured, and the whole system was in a quasi-stationary potential. The EIS measurement ranged from $0.1 \mathrm{MHz}$ to $10 \mathrm{MHz}$, and the amplitude of the signal was $10 \mathrm{mV}$. The scanning potential was $-0.5 \mathrm{~V}_{\mathrm{SCE}}$ to $0.5 \mathrm{~V}_{\mathrm{SCE}}$, and the scanning rate was $2 \mathrm{mV} / \mathrm{s}$.

\section{Table 2 Laser heat treatment conditions}




\begin{tabular}{|ll|}
\hline Treatment & Condition \\
\hline T6 & $120^{\circ} \mathrm{C} \times 16 \mathrm{hr}$ \\
\hline HTPP & $460{ }^{\circ} \mathrm{C} \times 0.5 \mathrm{~h}+120^{\circ} \mathrm{C} \times 16 \mathrm{hr}$ \\
\hline LHTPP(950) & $950 \mathrm{~W}, 3 \mathrm{~mm} / \mathrm{s}+120^{\circ} \mathrm{C} \times 16 \mathrm{hr}$ \\
\hline LHTPP(1000) & $1000 \mathrm{~W}, 3 \mathrm{~mm} / \mathrm{s}+120^{\circ} \mathrm{C} \times 16 \mathrm{hr}$ \\
\hline $\operatorname{LHTPP}(1050)$ & $1050 \mathrm{~W}, 3 \mathrm{~mm} / \mathrm{s}+120^{\circ} \mathrm{C} \times 16 \mathrm{hr}$ \\
\hline $\operatorname{LHTPP}(1100)$ & $1100 \mathrm{~W}, 3 \mathrm{~mm} / \mathrm{s}+120^{\circ} \mathrm{C} \times 16 \mathrm{hr}$ \\
\hline
\end{tabular}

\section{Results And Discussion}

\subsection{Microstructure}

Optical Microscope, the size of the grain can be seen intuitively. The obvious size difference can be seen after the contrast between the two graphs. It is shown that the grain has a tendency to become smaller by laser. After laser treatment, there are fewer defects between the grains. It is also related to the preprecipitation at high temperature. The precipitation phase and grain boundary in the matrix will be analyzed in more detail.

Bright-field TEM images of alloy with different process are shown in figure 3. In figure 3(a), the sample was treated with T6 temper. The grain interior precipitates were big and distribute uniformly, while grain boundary precipitates were continuous. The sequence of the precipitation of the AA7075 can be

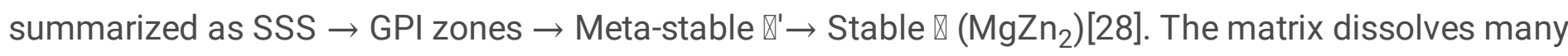
low stability precipitates with the HTPP process. The precipitates precipitated continuously at the grain boundary and gathered near the grain boundary. The corrosion channel of the alloy was formed at the grain boundary. The grain boundary precipitates had lower potential than the matrix, so the corrosion would begin to precipitate at the grain boundary of the alloy. As a result, the corrosion resistance of the alloy became worse and the grain boundary corrosion was formed. The size and distribution of the precipitates could be adjusted by HTPP process. After HTPP process, the morphology of the matrix was not different from that with T6 temper. But at the grain boundary, the precipitates at the grain boundary changed continuous to discontinuity. It led to the change of potential at the grain boundary. Due to the discontinuity distribution of precipitates, the corrosion channel was blocked, enhanced the corrosion resistance of the alloy. After LHTPP process, the precipitated in the matrix became finer, and enhanced the corrosion resistance of the alloy in the matrix. At the grain boundary, the precipitates at the grain boundary were discontinuity. The corrosion resistance was enhanced at the grain boundary. With the change of laser power, precipitates free zones (PFZs) also changed widen and narrow. Similar ideas were found in recent reports[26-27]. Typically, $₫$ phases were observed to be anodic to the matrix. However,

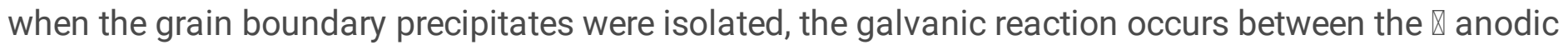
precipitates and the matrix. Thus, an active corrosion path was formed. Therefore, the corrosion 
resistance of LHTPP(1000) process was better than those of the other samples treated with HTPP or T6 treatment. Grain boundary precipitates had potential differences with the other electrodes around the grain boundaries, leading to the anodic dissolution of the precipitates. With the increasing laser power, the surface of the alloy was melted, and when the laser was swept, the surface of the alloy was resolidified. The precipitates phase was re-accumulated at the grain boundary, and the corrosion was deteriorated.

The grain boundary was completely corroded and appeared black. Some precipitates in the matrix have been corroded first, but it is noteworthy that the precipitation at the grain boundary were not continuous, the corrosion process of the alloy was difficult. The corrosion of the alloy will be restricted by the small precipitation, and will slow down the overall corrosion rate.

The GPI zone and metastable ख' phase can be clearly observed by HRTEM, it is also the key to enhance corrosion resistance. As corrosion proceeds, these are more difficult to corrode than the $₫$ phase and increased the difficulty of corrosion. This is the key to improve AA7075 by laser treatment. it is also related to the new passivation layer in nyquist data in electrochemical corrosion. These metastable phases can be formed near the alloy surface. Compared to the $\otimes$ phases, these phases have better corrosion resistance because they are not fully formed and require a larger potential to advance the corrosion, thus forming a passivation layer delaying the alloy corrosion. The traditional heat treatment process can only be carried out by shortening the heat treatment time, but it often leads to insufficient energy to achieve the desired results. And the laser processing speed is fast and the energy is high. This process can be completed.

\subsection{Effects of LHTPP process on exfoliation corrosion resistance}

The images of the experimental surfaces after the exfoliation corrosion are shown in figure 6 . It is observed that the sample which treated with LHTPP process have better resistance of corrosion than T6 and HTPP treatment. With increasing laser power, the corrosion resistance of the sample first decreased and then increased. From figure 6(a), it could be found that the corrosion exposure induces an extensive network of micro cracks. The surface had been corroded and continued to corrode the alloy under surface. After LHTPP process, the corrosion resistances of the alloy were improved. Different from the heat treatment furnace, the energy of laser treatment was relatively concentrated and the effect was remarkable. Comparing the fig 6 (b) with the (c), it can be clearly found that the corrosion resistance of the alloy surface is relatively good after laser treatment, and there is no large exfoliation on the surface, only small pits and pitting corrosion occur.

Generally, for the AA7075, the corrosion resistance depends on the grain and grain boundary precipitation of the alloy. The precipitation of the grain boundary becomes discontinuous with LHTPP process, and blocks the corrosion channel. The exfoliation corrosion from the macroscopic point of view proves that the laser treatment has a significant improvement on the corrosion resistance of the alloy. Next, the above view can be further proved by the corrosion depth on the side of the exfoliation corrosion experiment. 
Figure 7 was shown the intergranular corrosion on the exfoliation corrosion of the alloy. These can be more obvious proof of the corrosion resistance of the alloy, from the side, the corrosion resistance of the alloy after laser treatment is the best.

The above conclusion can prove that laser treatment can improve the corrosion resistance of the alloy, but it can not get more scientific authority only from the macro point of view. As the beginning of AA7075 corrosion is generated from the intergranular. Therefore, it is very scientific to explore the corrosion of the alloy under microscopic conditions through the depth of intergranular corrosion. However, the experimental results show that different laser power may have different effects on the corrosion resistance of the alloy. In the following experiments, three groups of different laser power will be added to study the intergranular corrosion depth of the same experiment. Through this experiment, reasonable laser parameters can be obtained more accurately.

\subsection{Effects of LHTPP process on intergranular corrosion resistance}

Figure 8 is shown the typical scanning electron microscopy images for the cross-sections of the alloy treated with different treatment. As shown in figure 8(a), when the sample was treated with T6 temper, the alloy reached the conventionally peak-aged condition and exhibited severe IGC with a maximum corrosion depth of $170 \mu \mathrm{m}$. It could be observed that the corrosion develop inward along the grain boundary of the alloy. As shown in figure 8(b), the sample was treated with HTPP process, As compared to the T6 sample, the HTPP process sample was still susceptible to IGC, but with a decreased maximum corrosion depth of $70 \mu \mathrm{m}$. When the sample was treated with LHTPP process, the sample was not susceptible to IGC in figure 8(c), The corrosion depth and rating of the samples under different heat treatments were listed in Table 3.

\section{Table 3 Corrosion rating results of alloy with different process}

\begin{tabular}{|lllllll|}
\hline Treatment & T6 & HTPP & LHTPP(950) & LHTPP(1000) & LHTPP(1050) & LHTPP(1100) \\
\hline EXCO rating & ED & EC & EC & EB & EC & ED \\
\hline IGC depth $/ \mu \mathrm{m}$ & 170 & 100 & 85 & 17 & 23 & 146 \\
\hline
\end{tabular}

In general, the IGC of aluminum alloy is divided into the following corrosion mechanisms. First, IGC is a localized electrochemical corrosion, as a result of the difference in the corrosion potential of the second phase component and the matrix[29,30].

Second, due to the preferential precipitation of the precipitates at the grain boundary, the grain boundary precipitates are continuously formed to a completely corrosion channel, the corrosion is rapidly corroded along the grain boundary. Finally, the continuous grain boundary corrosion is formed. In T6 temper, the grain boundary precipitates of the alloy were continuously distributed, thus forming a deep IGC. When the samples were treated with HTPP process, the grain boundary precipitates began to change the continuous distribution to the discontinuous distribution, and the corrosion channel of the alloy was 
blocked. The IGC sensitivity of the alloy was lower than that with T6 temper. When the sample was treated with LHTPP process, the internal precipitates of the alloy became fine and diffuse, and the distribution was uniform. It caused the potential difference between the second phase and the matrix to be reduced, making the corrosion more difficult to carry out. At the grain boundary, the discontinuous grain boundary precipitates were also formed. Make the sample insensitive to IGC. However, with increasing laser power, the surface of the alloy began to melt. Because the laser energy was high and the cooling speed was fast, the surface of the alloy was in a state of re-solidification. So, the alloy continued to be sensitive to IGC. It can be seen that LHTPP process with a reasonable laser parameter can completely reduce the IGC sensitivity of the alloy. intergranular corrosion depth can prove that laser treatment can indeed improve the corrosion resistance of AA7075. intergranular corrosion is due to the tiny electrochemical corrosion produced in the crystal. Therefore, electrochemical analysis equipment will be used to explore the causes of corrosion resistance enhancement and analysis.

\subsection{Effects of LHTPP process on electrochemical corrosion resistance}

Figure 9 is shown the polarization curves of the AA7075 treated with different process in $0.1 \mathrm{~mol} \mathrm{NaCl}$. In generally, the corrosion potential is the primary tool for reacting the corrosion reaction[24]. When the sample was treated with T6 temper, the corrosion potential of the alloy was small. The alloy was more susceptible to corrosion. However, the corrosion potential of the alloy was increased after the HTPP process of the sample. it also proved that the HTPP process can enhance the corrosion resistance of the alloy. When the alloy was treated with LHTPP process, the corrosion potential of the alloy continued to increase. When the alloy was treated with LHTPP(1000) process, the corrosion potential of the alloy was the largest. It indicated that in the same conditions, the alloy needs a larger potential difference to corrode. It was observed from figure 10 that when the potentials were shifted to the anodic domain, the anodic current densities increase rapidly. This potential was considered to be the oxide breakdown or pitting potential that led to localized corrosion. However, when the alloy was treated with LHTPP process, the potential of the alloy increased and the current decreased in the anode region. It indicated that the passivation layer was formed after corrosion, and the alloy did not transition from local corrosion to intergranular corrosion, but reformed a new pitting corrosion phenomenon. Because of discontinues grain boundary precipitation and the blocking corrosion channels. The completely intergranular corrosion could not be formed. It is due to the increasing of corrosion resistance of the alloy with LHTPP process. However, with the laser power continued to increasing, the alloy had a surface melting phenomenon, and the alloy began to form a completely corrosion channel, resulting in a deterioration of the corrosion resistance of the alloy.

Figure 11 is shown the equivalent circuit used to model the impedance parameters for the $\mathrm{Al}-\mathrm{Zn}-\mathrm{Mg}-\mathrm{Cu}$ alloy. The physical significance of the elements of the equivalent circuit can be described as follows: Rs corresponds to the solution resistance, and $\mathrm{R}$ corresponds to the resistances of the porous and barrier layers. CPE is constant phase angle[25]. There is a certain linear relationship between the capacitance and the resistance. It can be expressed by the formula. When the model shown in figure 11(a) is used to analyze the impedance map of laser treatment, it is found that the results obtained do not match the 
facts. Hence, it is not correct to use only a single model to simulate AA7075 electrochemical corrosion under different heat treatment processes. Therefore, a new simulation model will be used to compare the laser heat treated samples. Figure 11 is shown the Nyquist diagrams of the AA7075 treated with different processes. The Nyquist diagrams of the samples were different. when the alloy were treated with T6 temper, HTPP process and LHTPP process. There was only one tolerance arc in the impedance parameters indicating that the whole corrosion process was controlled by the activation polarization, and there was no concentration polarization in the whole reaction process. The radius of the arc tolerance could reflect the corrosion resistance of the alloy. The radius of the HTPP process was the maximum and the resistance was the highest. However, the experimental results of intergranular corrosion do not agree with this, so the data of laser heat treatment are fitted by a new simulation model, which is found to be consistent with the previous conclusions.

Figure 12 is shown the Nyquist diagrams of the AA7075 treated with different laser power. With the LHTPP process, a second anti-arc was present in the curve. It indicated that the alloy did not exhibit intergranular corrosion and no corrosion channel was formed inside the alloy. Instead, a new passivation layer was formed. This corresponds to the previous data in the polarization curve. With the laser power increasing, the radius of the second arc was first increased and then decreased it indicated that the resistance of the passivation layer also increased first and then decreased. The corrosion resistance of the alloy was the best when the laser power is $1000 \mathrm{~W}$. However, with the increase of the laser power, the surface of the alloy had a melting phenomenon, the corrosion resistance was very poor. Therefore, the laser surface treatment can obviously improve the corrosion resistance of the alloy, but the excessive laser power can melt the alloy. Reasonable laser power can preferentially form a passivation layer on the alloy surface. It is the key to enhance the corrosion resistance of the alloy.

\section{Conclusions}

Laser high temperature pre-precipitation process was performed to improve the microstructures and corrosion resistance of the AA7075. It was observed that grain boundary precipitates obtained with the laser high temperature pre-precipitation process plays an important role in corrosion resistance.

Compared with HTPP process, the sample with LHTPP process has less corrosion susceptibility, revealing that a suitable laser process can effectively improve the corrosion resistance. Exfoliation corrosion and IGC could prove that. Polarization curves and EIS reveal the change in the corrosion resistance in the AA7075 with LHTPP process. Discontinuous grain boundary precipitates and wide PFZs of the sample increase the corrosion resistance. The improved corrosion resistance of LHTPP process is due to the increased spacing of the grain boundary precipitates. The discontinuous grain boundary precipitates block the corrosion channels, make the intergranular corrosion transform to pitting corrosion.

\section{Declarations}

\section{Acknowledgement}


This research was financially supported by the program for National Key Research and Development Plan (2017YFB1104000), the National Natural Science Foundation of China (51574167) and the Science and Technology Program of Liaoning Provincial Department of Education (LJGD2020010).

Funding (information that explains whether and by whom the research was supported)

This research was financially supported by the program for National Key Research and Development Plan (2017YFB1104000), the National Natural Science Foundation of China (51574167) and the Science and Technology Program of Liaoning Provincial Department of Education (LJGD2020010).

Conflicts of interest/Competing interests (include appropriate disclosures)

No conflicts of interest, never contributed.

Availability of data and material (data transparency)

All the data of this paper are available.

Code availability (software application or custom code)

My manuscript does not contain the code.

Consent to participate (include appropriate statements)

Consent for publication (include appropriate statements)

I agree to publish in the journal Advanced Manufacturing Technology.

I agree to participate in this journal.

\section{Ethics approval (include appropriate approvals or waivers)}

My experiment is reasonable and legal, in line with national standards, in line with ethics.

As for the author's contribution, I will not make a statement here.

\section{References}

[1] Sepehrband P, Esmaeili S. Application of recently developed approaches to microstructural characterization and yield strength modeling of aluminum alloy AA7030[J]. Materials Science and Engineering: A, 2008, 487(1): 309-315.

[2] Marlaud T, Deschamps A, Bley F, Lefebvre W, Baroux B. Evolution of precipitate microstructures during the retrogression and re-ageing heat treatment of an Al-Zn-Mg-Cu alloy[J]. Acta Materialia, 2010, 58(14): 4814-4826. 
[3] Wu Q, Li D P, Ren L. Detecting milling deformation in 7075 aluminum alloy thin-walled plates using finite difference method[J]. International Journal of Advanced Manufacturing Technology, 2016, 85(5): 1291-1302.

[4] Lin Y C, Li L T, Xia Y C. Hot deformation and processing map of a typical Al-Zn-Mg-Cu alloy[J]. Journal of Alloy and Compounds, 2013, 550: 438-445.

[5] Abolfazl A, Ali K T, Kourosh K T. Recent Advances in Ageing of 7xxx Series Aluminum Alloy: A Physical Metallurgy Perspective[J]. Journal of Alloy and Compounds, 2019, 781: 945-983.

[6] Chen R R, Qin G. Composition design of high entropy alloys using the valence electron concentration to balance strength and ductility[J]. Acta Materialia, 2018, 144: 129-137.

[7] Qin G, Chen R R. A novel face-centered-cubic high-entropy alloy strengthened by nanoscale precipitates[J]. Scripta Materialia, 2019, 172: 51-55.

[8] Dey S, Gun M K, Chattoraj I. Effect of temper on the distribution of pits in AA7075 alloys[J]. Corrosion Science, 2008, 50(10): 2895-2901.

[9] Lee Y S, Koh D H, Kim H W. Improved bake-hardening response of Al-Zn-Mg-Cu alloy through pre-aging treatment[J]. Scripta Materialia, 2018, 147: 45-49.

[10] Wang D, Ni D R, Ma Z Y. Effect of pre-strain and two-step aging on microstructure and stress corrosion cracking of 7050 alloy[J]. Materials Science and Engineering: A, 2008, 494(1): 360-366.

[11] Dixit M, Mishra R S, Sankaran K K. Structure-property correlations in Al 7050 and Al 7055 highstrength aluminum alloys[J]. Materials Science and Engineering: A, 2008, 478(1): 163-172.

[12] Jiang D M, Liu Y, Liang S, Xie W L. The effects of non-isothermal aging on the strength and corrosion behavior of Al-Zn-Mg-Cu alloy[J]. Journal of Alloy and Compounds, 2016, 681: 57-65.

[13] Su R M, Su J H, Qu Y D, You J H, Li R D. Retrogression on corrosion behavior of spray formed Al7075[J]. Journal of Materials Research. 2017, 32(13): 2621-2627.

[14] Reda Y, Abdel-Karim R, Elmahallawi I. Improvements in mechanical and stress corrosion cracking properties in Al-alloy 7075 via retrogress and reaging[J]. Materials Science and Engineering: A, 2008, 485(1): 468-475.

[15] Su R M, Qu Y D, Li R D. Effect of aging treatments on the mechanical and corrosive behaviors of spray-formed 7075 alloy[J]. Journal of Materials Engineering \& Performance, 2014, 23(11): 3842-3848.

[16] Nandana M S, Bhat K U, Manjunatha C M. Effect of retrogression heat treatment time on microstructure and mechanical properties of AA7010[J]. Journal of Materials Engineering \& Performance, 2018, 27(4): 1628-1634. 
[17] Huang L P, Li S. Influence of high-temperature pre-precipitation on local corrosion behaviors of AlZn-Mg alloy[J]. Scripta Materialia, 2007, 56(4): 305-308.

[18] Chen K H, Huang L P. Effect of high-temperature pre-precipitation on microstructure and properties of 7055 aluminum alloy[J]. Transactions of Nonferrous Metals Society of China, 2003, 13(4): 750-754.

[19] Li S, Chen K H. Effect of high-temperature pre-precipitation on mechanical properties and stress corrosion cracking of Al-Zn-Mg alloys[J]. Transactions of Nonferrous Metals Society of China, 2003, 13(3): 585-589.

[20] Huang L P, Chen K H, Li S. Influence of grain-boundary pre-precipitation and corrosion characteristics of inter-granular phases on corrosion behaviors of an $\mathrm{Al}-\mathrm{Zn}-\mathrm{Mg}-\mathrm{Cu}$ alloy[J]. Materials Science and Engineering: B, 2012, 177(11): 862-868.

[21] Florando J N, Margraf J D, Reus J F, Anderson A T, McCallen R C. Modeling the effect of laser heating on the strength and failure of 7075-T6 aluminum[J]. Materials Science and Engineering: A, 2015, 640: 402-407.

[22] Ghosh K S, Mukhopadhyay S, Konar B, Mishra B. Study of aging and electrochemical behaviour of AlLiCuMg alloys[J]. Materials and Corrosion, 2013, 64(10): 890-901.

[23] Rout P K, Ghosh M M, Ghosh K S. Effect of solution pH on electrochemical and stress corrosion cracking behaviour of a $7150 \mathrm{Al}-\mathrm{Zn}-\mathrm{Mg}-\mathrm{Cu}$ alloy[J]. Materials Science and Engineering: A, 2014, 604: 156-165.

[24] Sha G, Cerezo A. Kinetic monte carlo simulation of clustering in an Al-Zn-Mg-Cu alloy (7050)[J]. Acta Materialia, 2005, 53(4): 907-917.

[25] Chen S Y, Chen K H, Peng G S, Jia L, Dong P X. Effect of heat treatment on strength, exfoliation corrosion and electrochemical behavior of 7085 aluminum alloy[J]. Materials Design, 2012, 35: 93-98.

[26] Zhao Y H, Liu J Z, Topping T D, Lavernia E J. Precipitation and aging phenomena in an ultrafine grained Al-Zn alloy by severe plastic deformation[J]. Journal of Alloy and Compounds, 2021, 851: 57-65.

[27] Zhang Qi, Zhu Y M, Gao X, Wu Y X, Christopher H. Training high-strength aluminum alloys to withstand fatigue[J]. Nature Communications, 2020, 11(1): 5198.

[28] Aarabi H, Alizadeh M. Improvement of microstructure and corrosion properties of AA7075 Al alloy by melt shearing process[J]. Materials Letter, 2020, 275: 128058.

[29] Zheng X Z, Castaneda H, Gao H J, Srivastava A. Synergistic effects of corrosion and slow strain rate loading on the mechanical and electrochemical response of an aluminium alloy[J]. Corrosion Science, 2019, 153: 53-61. 
[30] Zhang C H, Huang G J, Cao Y. Investigation on microstructure and localized corrosion behavior in the stir zone of dissimilar friction-stir-welded AA2024/7075 joint[J]. Journal of Materials Science, 2020, 55(30): 15005-15032.

\section{Figures}

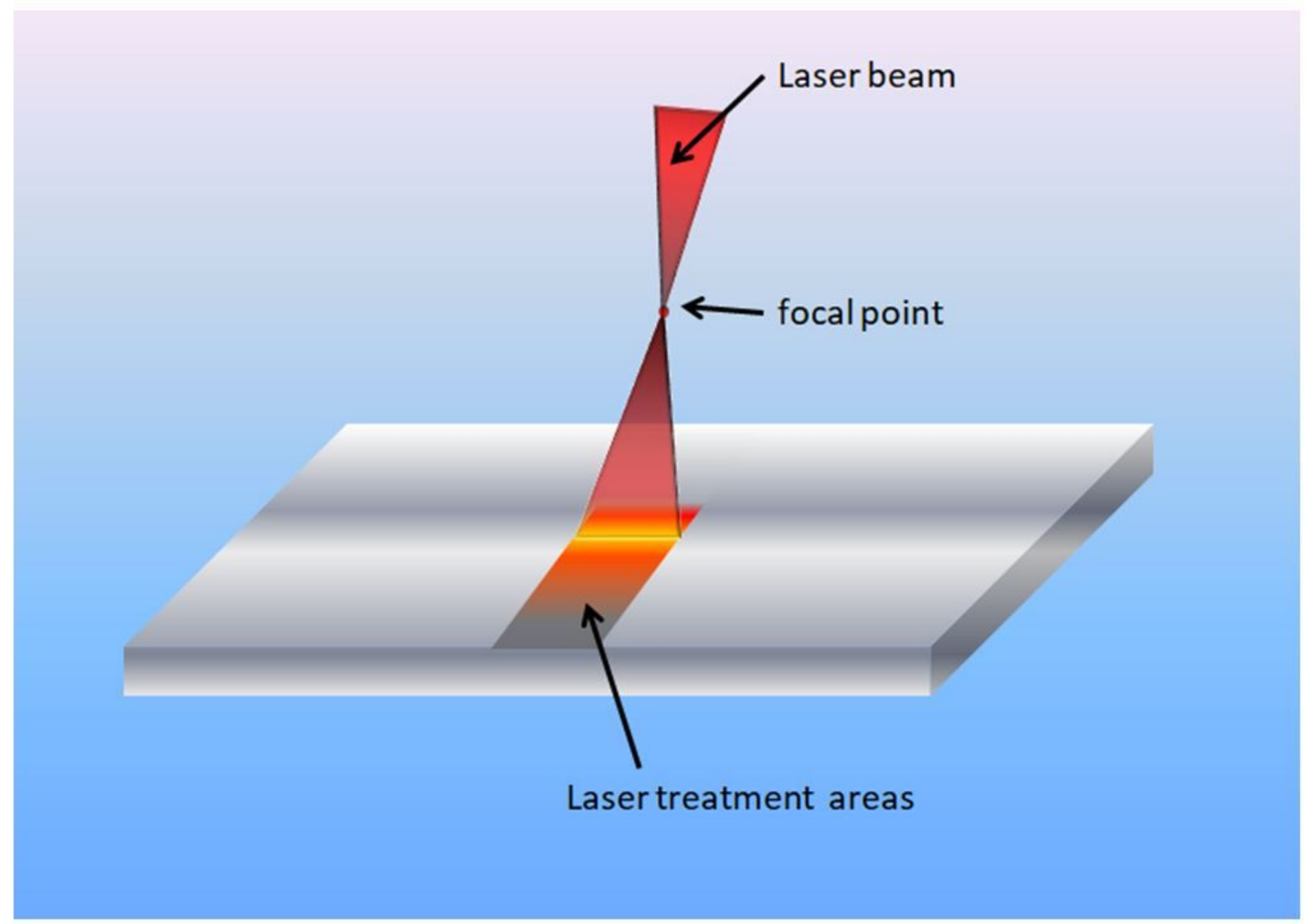

\section{Figure 1}

Schematic diagram of high temperature laser surface treatment process. 


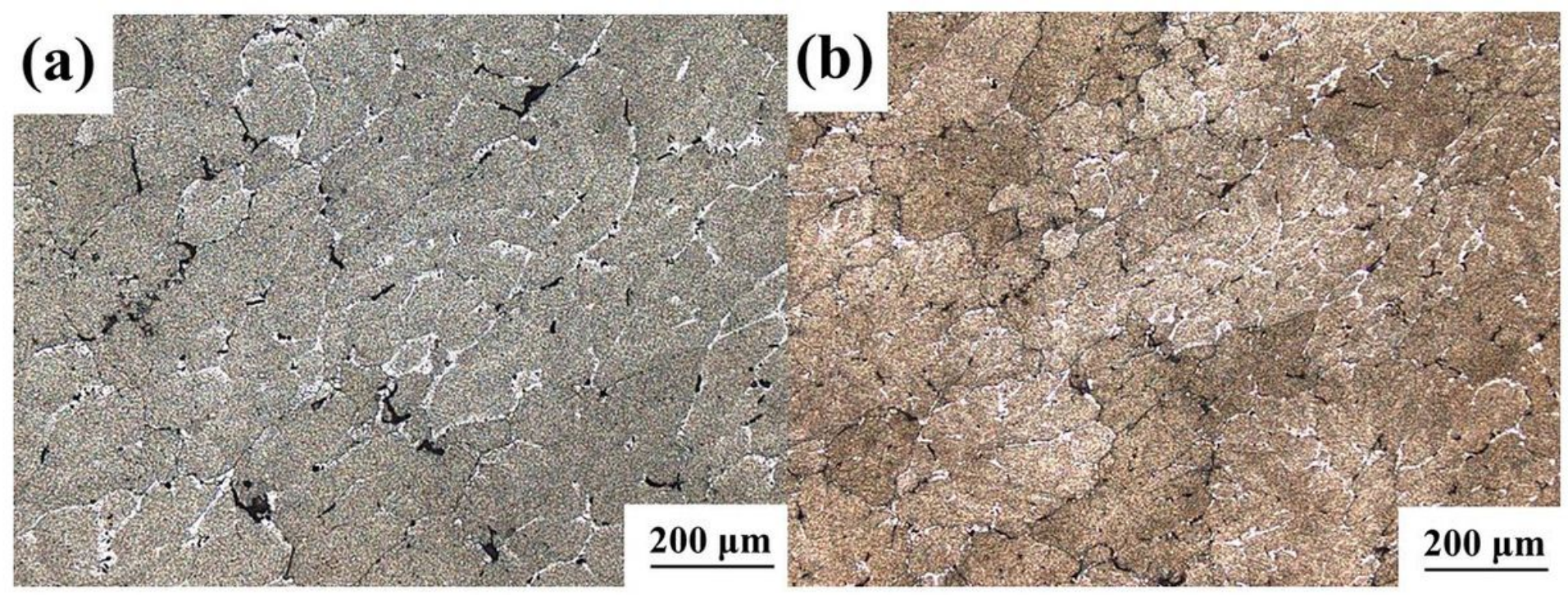

\section{Figure 2}

OM images of the AA7075 after different treatments: (a) T6, (b) LHTPP
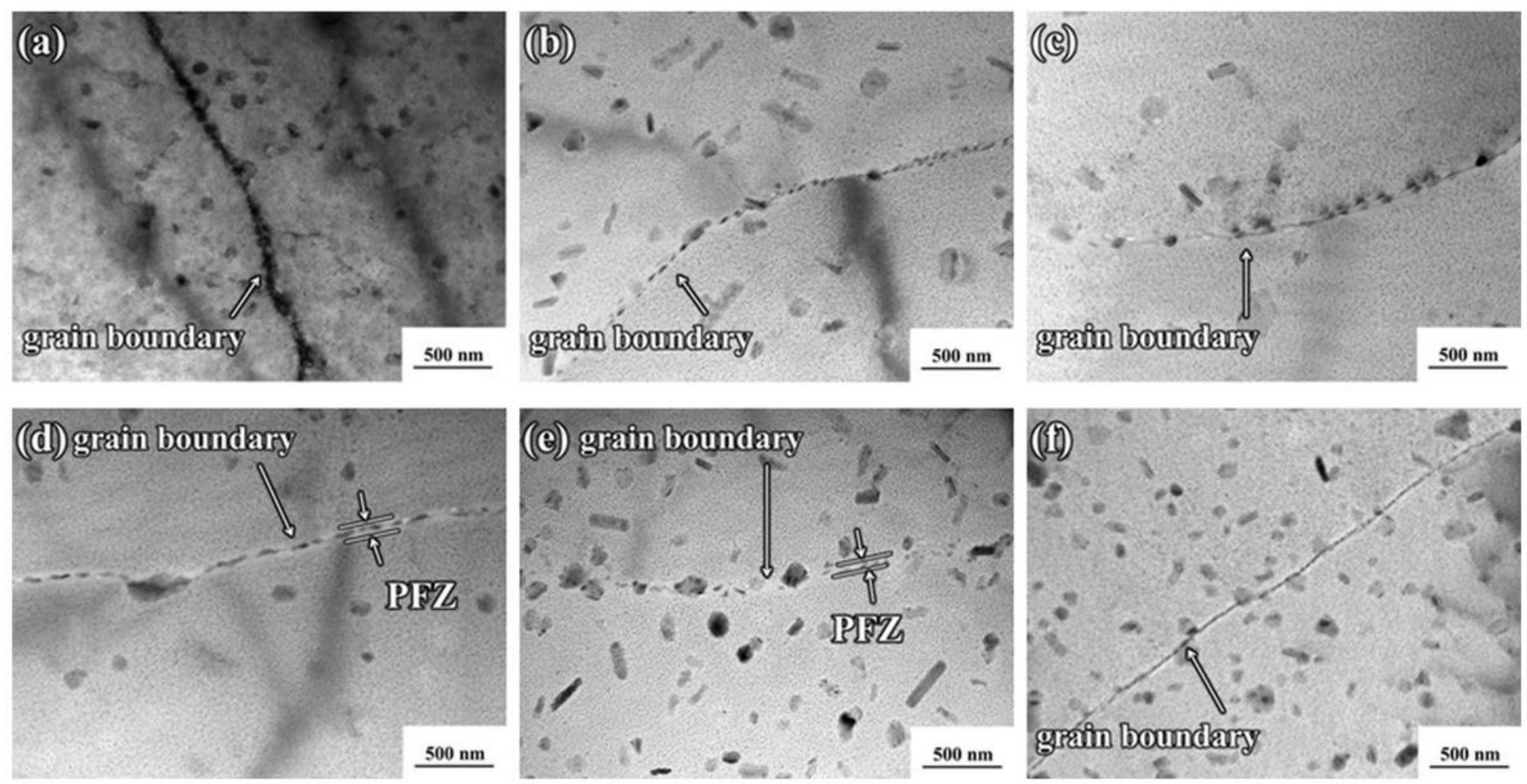

\section{Figure 3}

TEM images of the AA7075 after different treatments: (a) T6, (b) HTPP, (c) LHTPP(950), (d) $\operatorname{LHTPP}(1000)$, (e) LHTPP(1050) and (f) LHTPP(1100) 


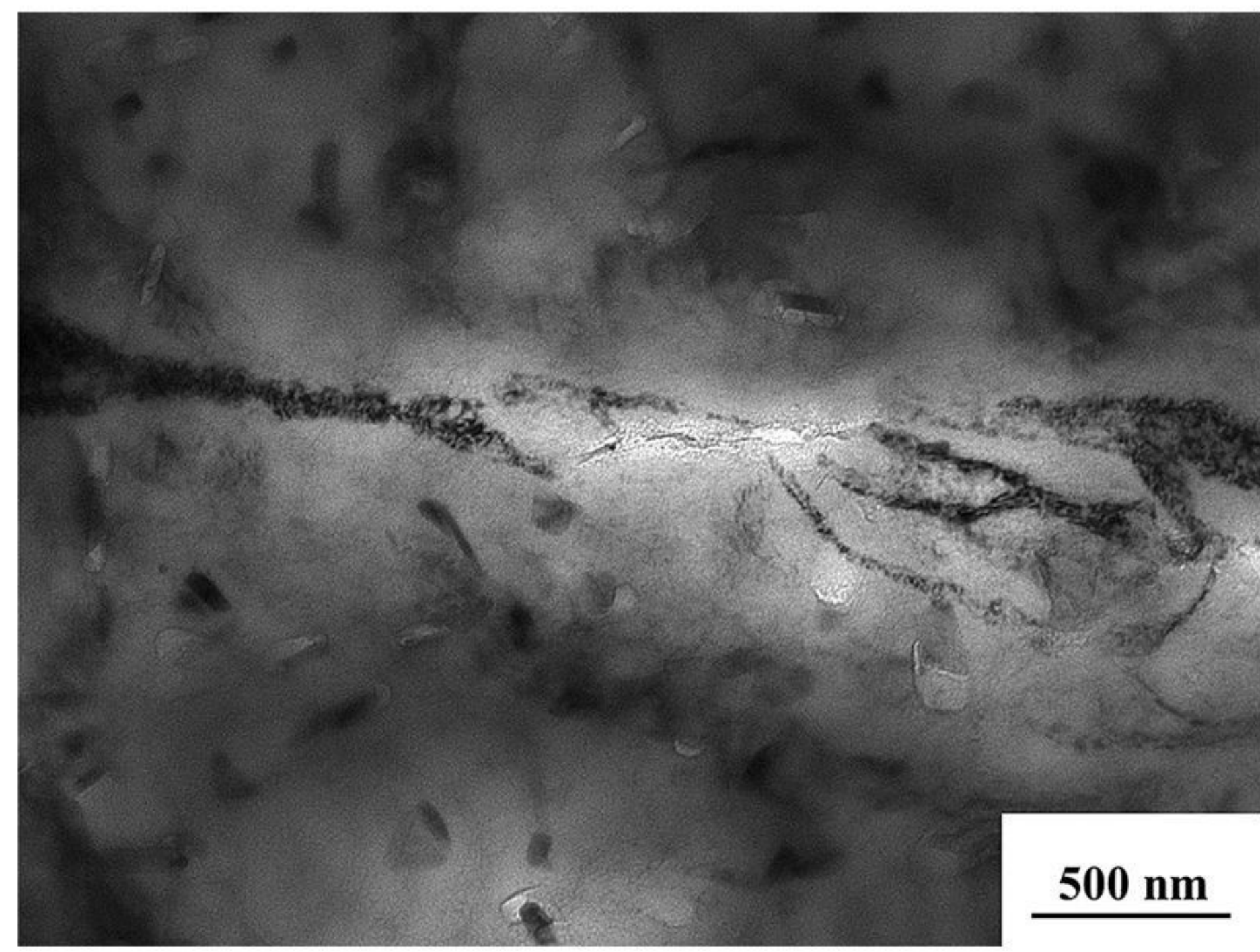

Figure 4

TEM images of the AA7075 with LHTPP after corroded. 


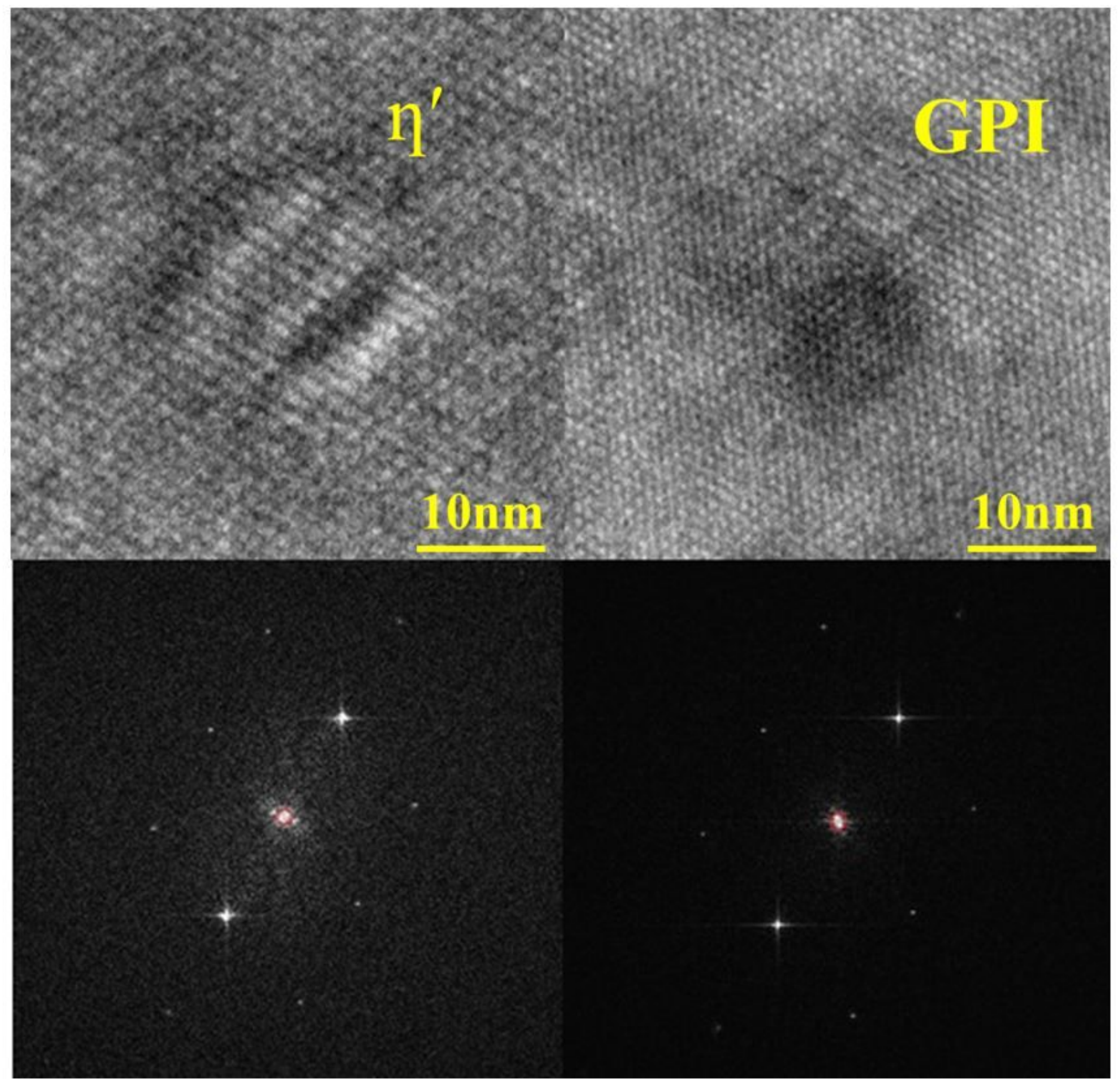

Figure 5

HRTEM images of the AA7075 with laser treatments 


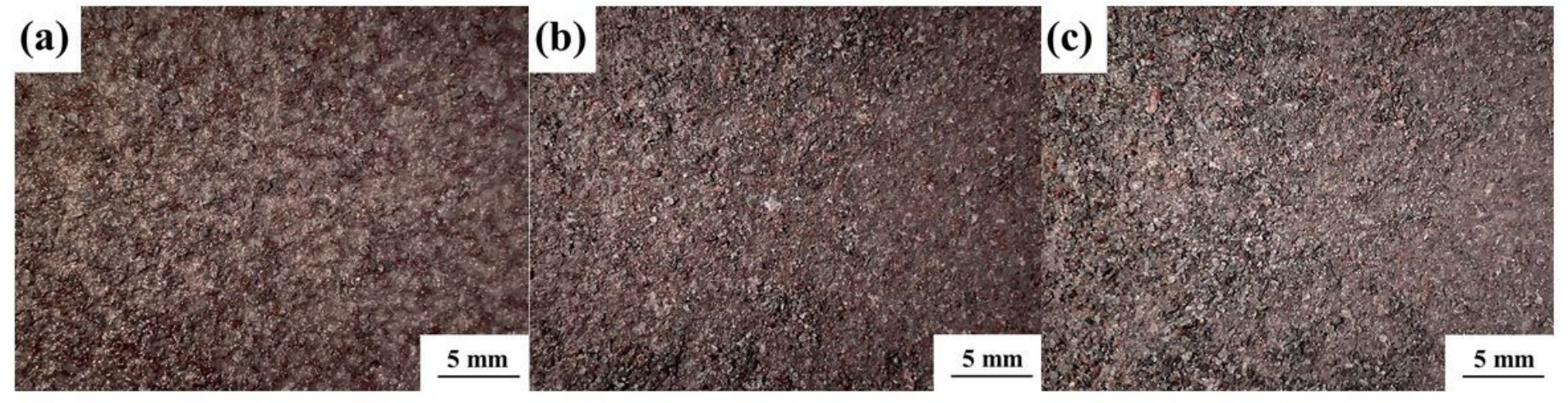

Figure 6

Exfoliation corrosion images of the AA7075 after different treatments: (a) T6, (b) HTPP, (c) LHTPP

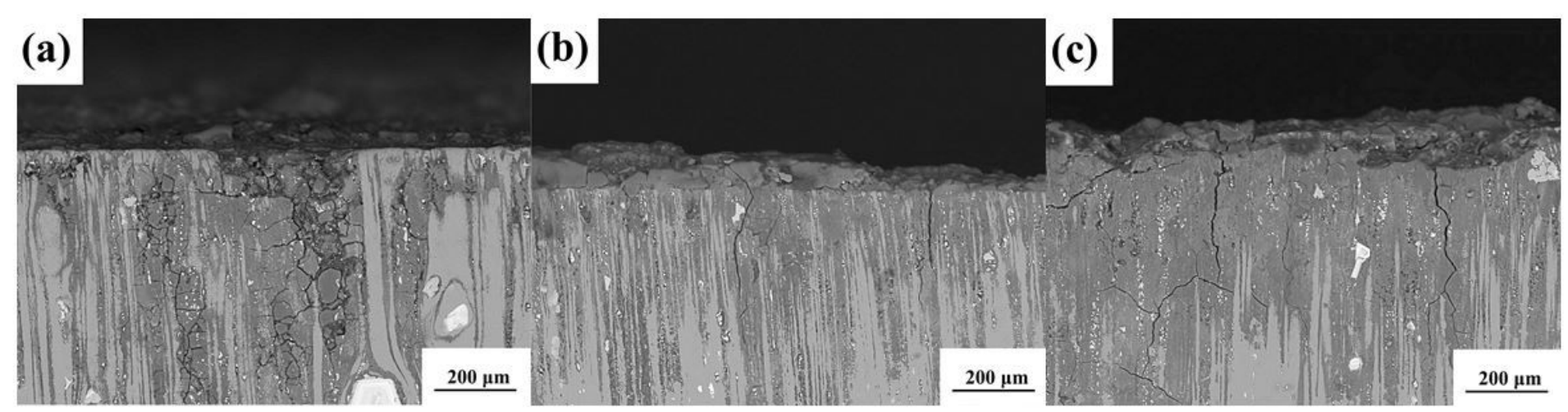

Figure 7

Exfoliation corrosion images of the AA7075 after different treatments: (a) T6, (b) HTPP, (c) LHTPP 

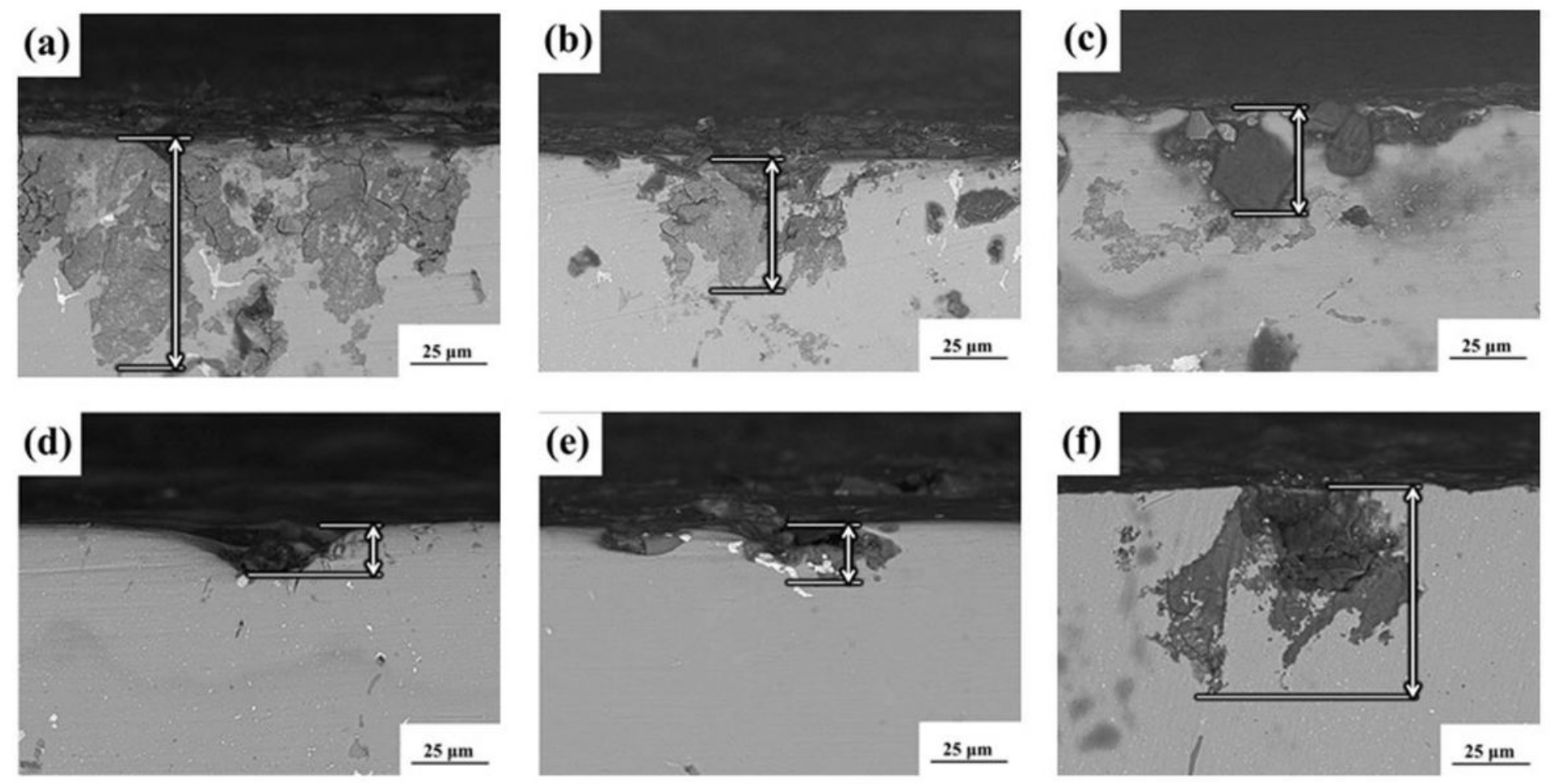

\section{Figure 8}

Intergranular corrosion images of the AA7075 after different treatments: (a) T6, (b) HTPP, (c) LHTPP(950), (d) LHTPP(1000), (e) LHTPP(1050) and (f) LHTPP(1100) 


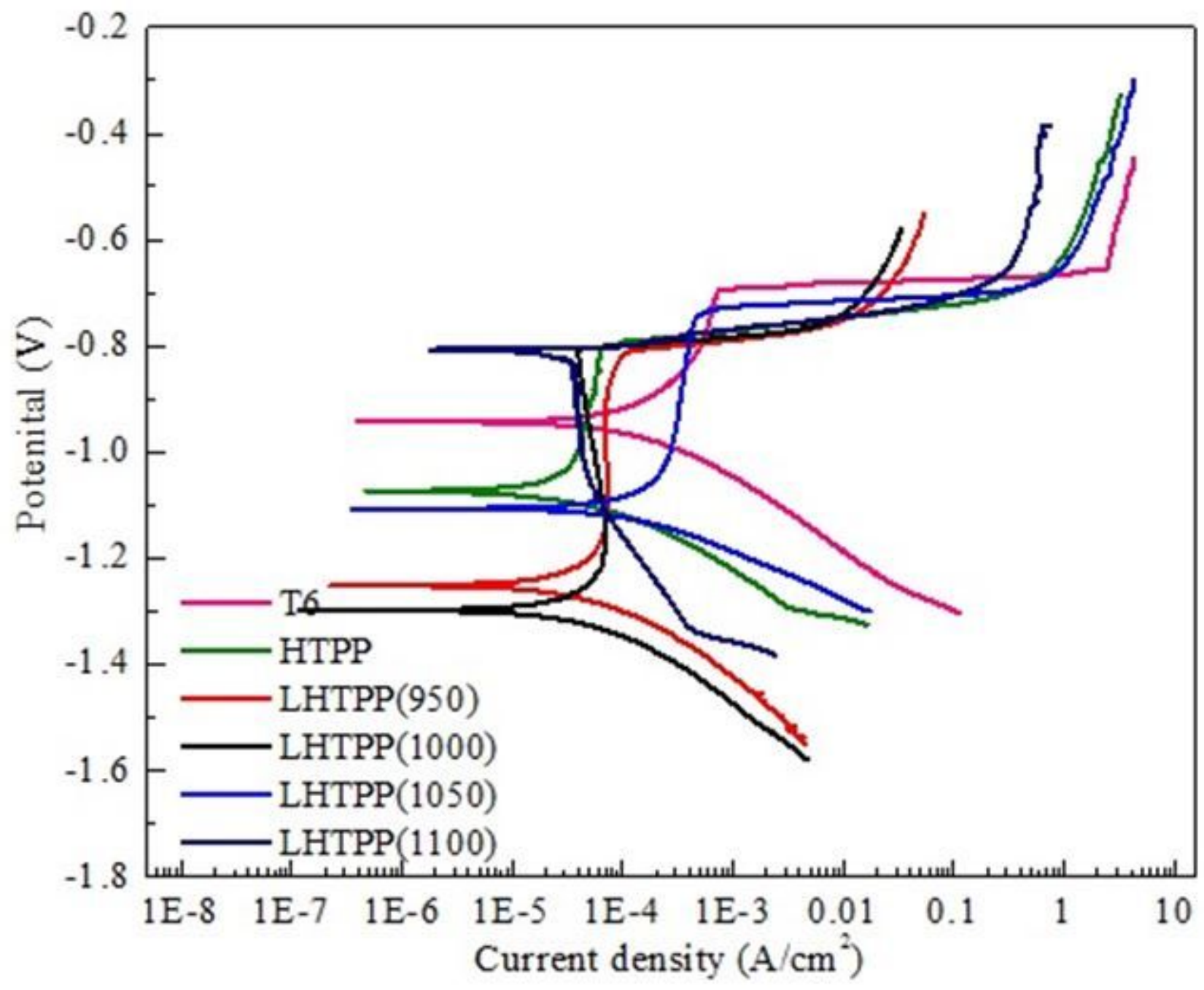

Figure 9

Polarization curves of the AA7075 treated with different heat treatments 


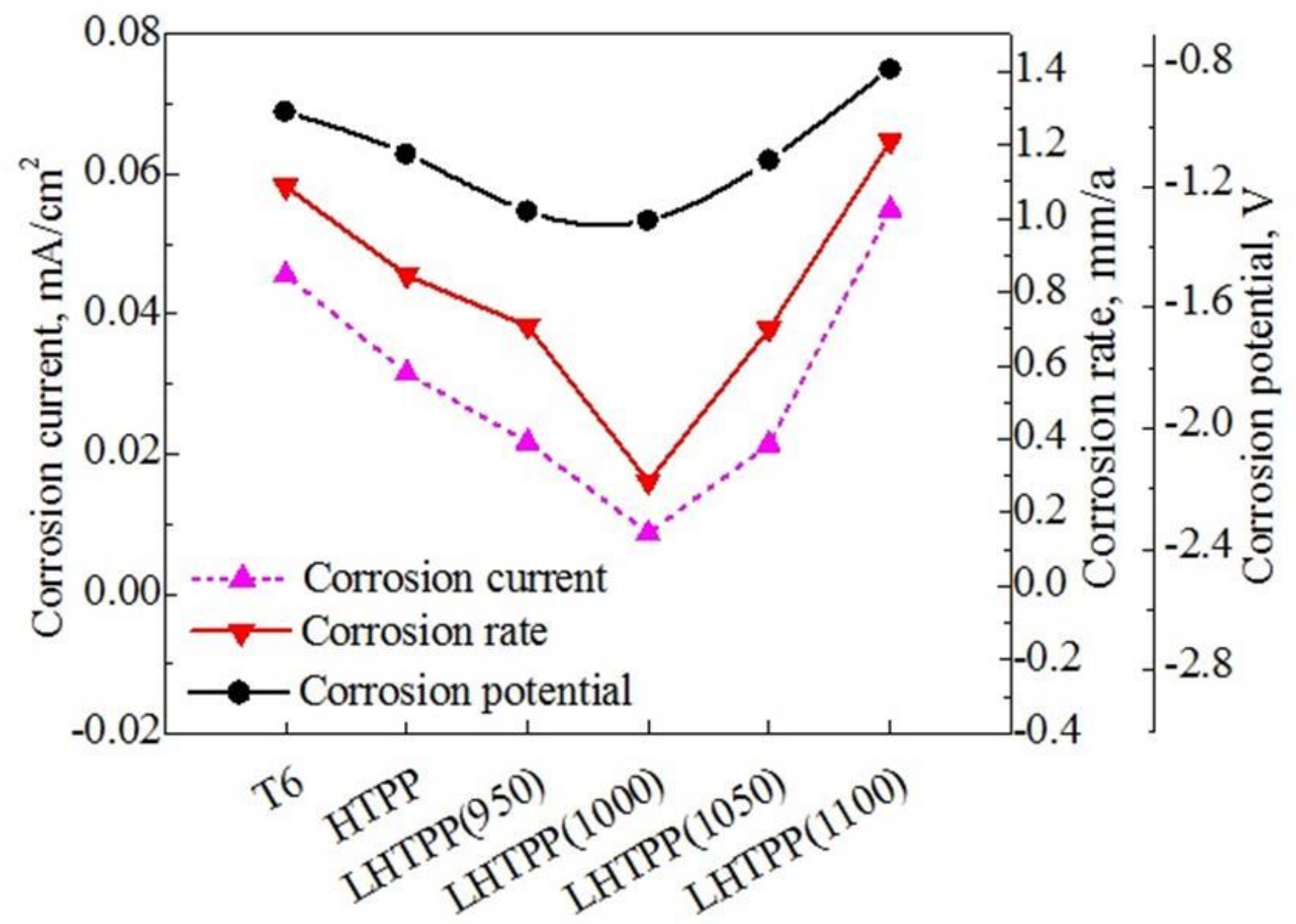

Figure 10

Corrosion rates, Icorr and Ecorr of the AA7075 treated with different heat treatments
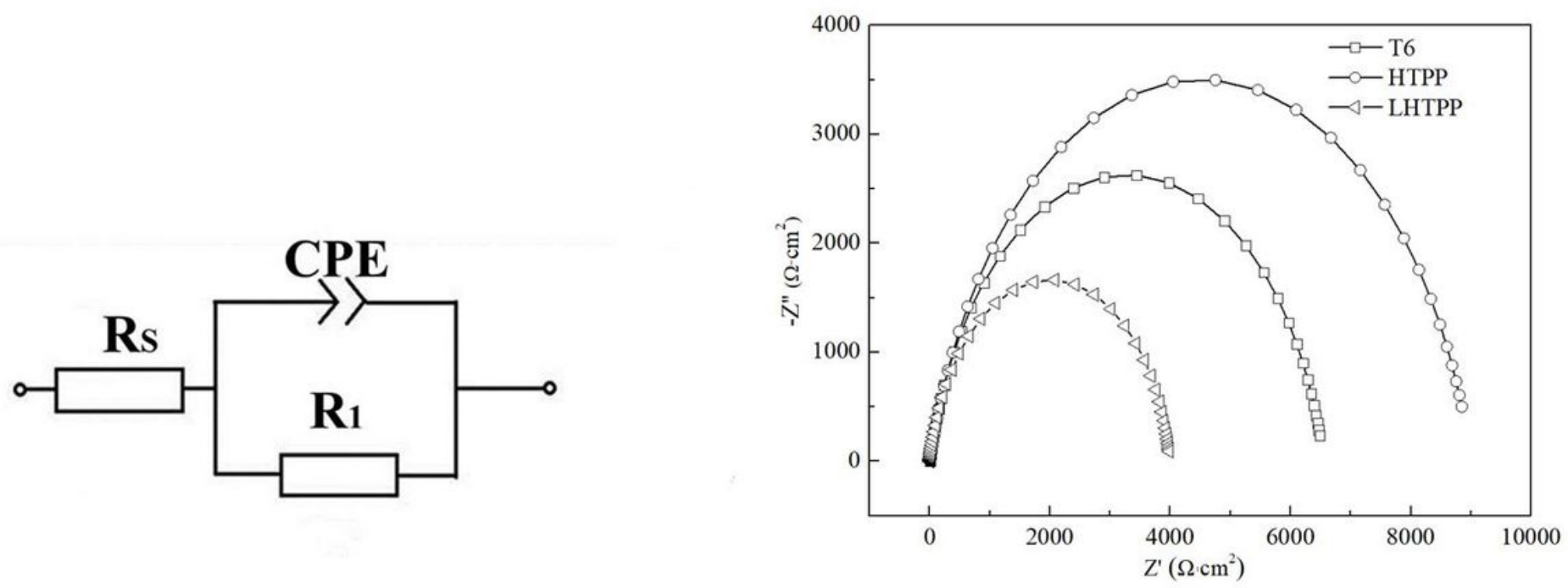

Figure 11 
Equivalent circuit used to model the impedance parameters for the AA7075 and EIS diagram for the samples with different heat treatment
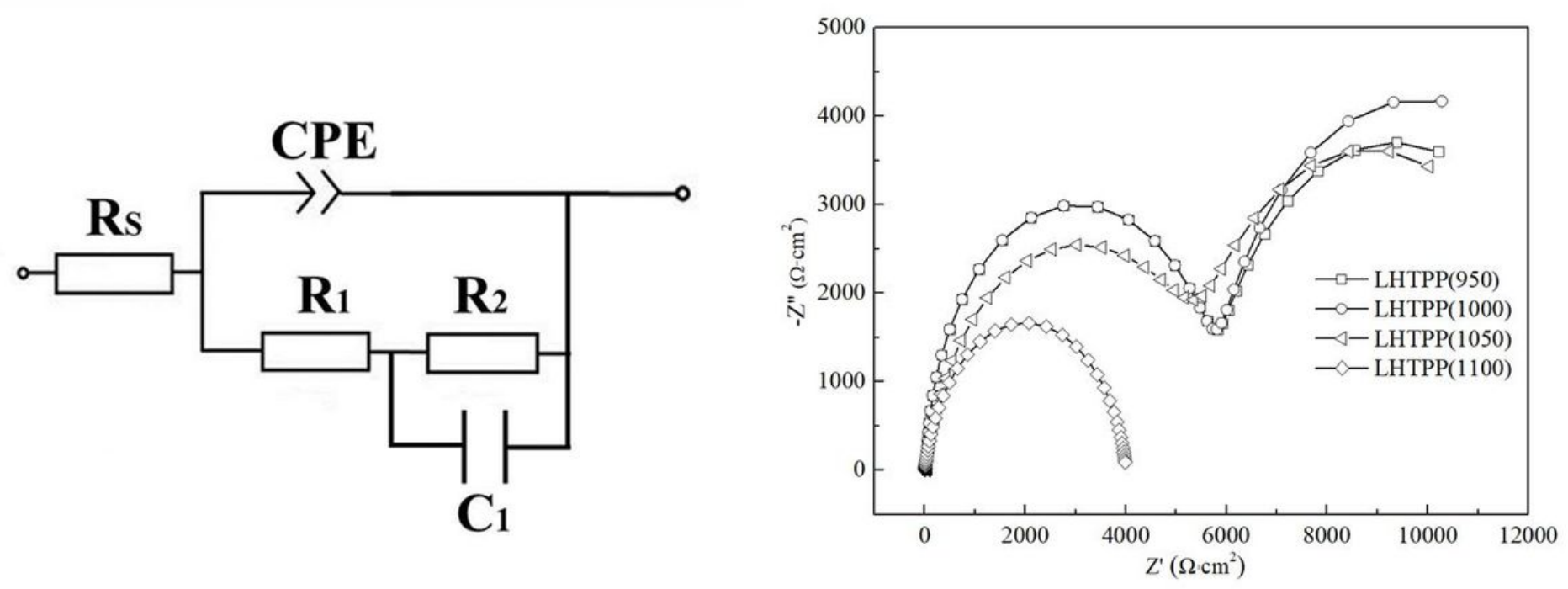

Figure 12

Equivalent circuits used to model the impedance parameters for the AA7075 and EIS diagram for the samples with different laser power 